
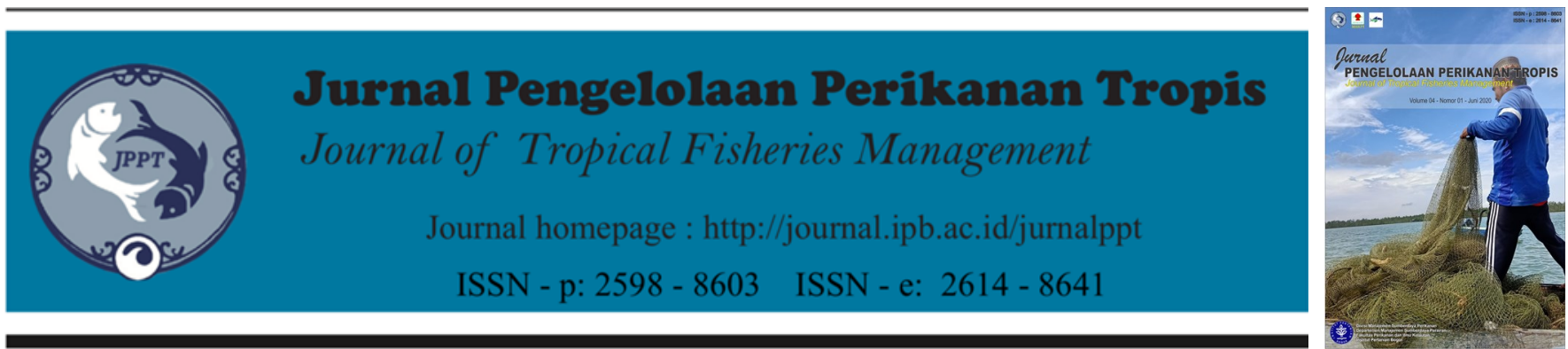

\title{
Produktivitas Sekunder Famili Crambidae di Sungai Cigambreng, Desa Tapos, Bogor
}

\author{
(Secondary Productivity of Crambidae Family in Cigambreng River, Tapos Village, Bogor)
}

\section{Arif Nurcahyanto $^{1}$, Ahyar Pulungan ${ }^{1}$, Didit Abdillah ${ }^{1}$, Muhammad Irfan Afif ${ }^{1}$, Mursalin Ishak ${ }^{1}$, Grin Tommy Panggabean ${ }^{1}$, Rizky Regina Kawirian ${ }^{1}$, Chichilia Q. A. Rahman ${ }^{1}$, Majariana Krisanti ${ }^{2}$}

\footnotetext{
${ }^{1}$ Program Studi Pengelolaan Sumberdaya Perairan, Sekolah Pasca Sarjana, Institut Pertanian Bogor

${ }^{2}$ Departemen Manajemen Sumberdaya Perairan, Fakultas Perikanan dan Ilmu Kelautan, Institut Pertanian Bogor
}

\begin{tabular}{|c|c|}
\hline ARTIKEL INFO & ABSTRAK \\
\hline $\begin{array}{l}\text { Article History } \\
\text { Recevied: } 02 \text { Maret } 2020 \\
\text { Accepted: } 14 \text { April } 2020\end{array}$ & \multirow{2}{*}{$\begin{array}{l}\text { Produktivitas sekunder adalah pembentukan biomassa organisme heterotrof dalam satuan waktu } \\
\text { tertentu termasuk biomassa yang hilang dalam satuan waktu tertentu. Famili Crambidae adalah } \\
\text { serangga yang memiliki fase larva akuatik. Jenis ini berpotensi menjadi hama bagi kegiatan } \\
\text { pertanian. Penelitian ini dilakukan di bulan Oktober } 2019 \text { selama satu bulan. Famili Crambidae yang } \\
\text { ditemukan terdiri dari dua genus yaitu Petrophila sp. dan Elophila sp. Kelimpahan Famili Crambidae } \\
\text { selama penelitian berkisar antara } 100 \text { ind } / \mathrm{m}^{2} \text { hingga } 422 \text { ind } / \mathrm{m}^{2} \text {. Produktivitas sekunder famili } \\
\text { Crambidae di Sungai Cigambreng, Desa Tapos, Bogor adalah } 47,7915 \mathrm{~g} / \mathrm{m}^{2} / \mathrm{bulan} \text {, biomassa yang } \\
\text { terbentuk adalah } 14,9669 \mathrm{~g} / \mathrm{m}^{2} \text { dan rasio P/B sebesar } 3,1931 \text {. }\end{array}$} \\
\hline $\begin{array}{l}\text { Kata Kunci: } \\
\text { Crambidae, produktivitas sekunder, } \\
\text { P/B ratio, sungai. }\end{array}$ & \\
\hline \multirow{2}{*}{$\begin{array}{l}\text { Keywords: } \\
\text { Crambidae, P/B ratio, river, secondary } \\
\text { productivity }\end{array}$} & $A B S T R A C T$ \\
\hline & \multirow{2}{*}{$\begin{array}{l}\text { Secondary productivity is the formation of biomass of heterotrophic organisms in units of time } \\
\text { including biomass that is lost in a certain time unit. The Crambidae family is an insect that has } \\
\text { aquatic larvae and will become an air insect after the larval phase. This family has the potential to } \\
\text { become a pest for agriculture. The study was conducted in October } 2019 \text { for one month. The } \\
\text { Crambidae family species found consists of two species, Petrophila sp. and Elophila sp. The } \\
\text { abundance of Crambidae during the study ranged from } 100 \text { ind } / \mathrm{m}^{2} \text { to } 422 \text { ind } / \mathrm{m}^{2} \text {. Secondary } \\
\text { productivity was analyzed by the size frequency method. The secondary productivity of the } \\
\text { Crambidae family in Cigambreng River was } 47,7915 \mathrm{~g} / \mathrm{m}^{2} / \mathrm{month} \text { the biomass formed was } 14,9669 \\
\mathrm{~g} / \mathrm{m}^{2} \text { and the P/B ratio was } 3,1931 \text {. }\end{array}$} \\
\hline $\begin{array}{l}\text { Korespondensi Author } \\
\text { Arif Nurcahyanto, } \\
\text { Program Studi Pengelolaan Sum- } \\
\text { berdaya Perairan, Fakultas Perikanan } \\
\text { dan Ilmu Kelautan, Institut Pertanian } \\
\text { Bogor. } \\
\text { Email: arifnurchayanto@gmail.com }\end{array}$ & \\
\hline
\end{tabular}

\section{PENDAHULUAN}

Produktivitas sekunder adalah pembentukan biomassa organisme heterotrof dalam satuan waktu tertentu (Benke 1993). Sebagai contoh, produktivitas tahunan adalah jumlah seluruh biomassa yang diproduksi oleh sebuah populasi dalam satu tahun (Benke \& Huryn 2007). Studi terhadap produktivitas memiliki peranan yang tinggi dalam memahami ekologi ekosistem, misalnya dinamika populasi suatu populasi tertentu, efek kegiatan antropogenik terhadap ekosistem, efek perubahan penggunaan catchment area, efek perubahan iklim pada ekosistem, aliran energi di ekosistem dan sebagainya (Dolbeth et al. 2012). Pemahaman tentang produktivitas sekunder berkaitan dengan pemahaman hubungan antara produktivitas dan biomasa. Biomasa (B) adalah pengukuran banyaknya massa jaringan hidup untuk populasi yang hadir pada satu saat dalam waktu (rata-rata selama beberapa waktu), dan unit massa (energi) per satuan luas (misalnya $\mathrm{g} / \mathrm{m}^{2}$ ) (Benke 1979 in Cesar \& Armendariz 2005). Produktivitas sekunder sangat dipengaruhi oleh biomasa, sedangkan rasio $\mathrm{P} / \mathrm{B}$ dipengaruhi oleh umur, ukuran tubuh dan suhu (Benke \& Huryn 2007).

Carlisle dan Clements (2003) menyatakan bahwa produksi sekunder merupakan fungsi pengukuran dinamika populasi, termasuk di dalamnya proses yang terjadi pada level individu, populasi maupun ekosistem. Produksi sekunder adalah ukuran komposit sebuah kepadatan populasi biota, biomassa dan pertumbuhan selama kurun waktu tertentu. Hewan-hewan herbivora yang mendapat bahan-bahan organik dengan memakan fitoplankton merupakan produsen kedua di dalam sistem rantai makanan.

Ordo Lepidoptera dengan famili Crambidae adalah spesies insekta yang fase larva-nya adalah 
larva akuatik (Lange 1996 in Stoops et al. 1998). Jenis insekta ini berperan besar dalam ekosistem akuatik sebagai kontrol biologis terhadap tumbuhan akuatik mengganggu, karena jenis ini merupakan jenis insekta akuatik yang herbivora/ grazers (Stoops et al. 1998). Chessman (2003) mengelompokkan jenis Lepidoptera dalam kelompok makroinvertebrata yang sangat toleran pada pencemaran. Carneiro et al. (2018) menyatakan bahwa insekta Lepidoptera merupakan hama yang mengganggu produksi kacang kedelai. Menurut Tofangsazi et al. (2014) jenis insekta famili Crambidae merupakan hama bagi produksi rumput untuk lapangan golf.

Bagian hulu sungai Cigambreng merupakan perairan sungai dengan berbagai kegiatan manusia di sekitarnya, seperti pemukiman, perkebunan peternakan dan wisata. Insekta dan makroinvertebrata merupakan bagian penting dalam aliran energi di perairan sungai. Berbagai penelitian terkait produktivitas sekunder makroinvertebrata di perairan telah dilakukan, namun masih jarang yang dilakukan pada Ordo Lepidoptera di perairan sungai. Selain sebagai sumber makanan trofik level di atasnya, Ordo Lepidoptera ini juga dapat menjadi hama pada saat dewasa, sehingga produktivitas sekunder Ordo Lepidoptera di perairan sungai menjadi penting diketahui sebagai masukan untuk pengelolaan ekosistem perairan Sungai Cigambreng. Penelitian ini bertujuan untuk mengetahui jenis Ordo Lepidoptera yang terdapat di perairan Sungai Cigambreng dan produktivitas sekundernya.

\section{METODE}

\section{Pengambilan Contoh}

Pengambilan contoh dilaksanakan pada 5 hingga 21 Oktober 2019 di Sungai Cigambreng, Desa Tapos, Kecamatan Tenjolaya, Kabupaten Bogor, Jawa Barat (Gambar 1). Sungai Cigambreng merupakan perairan sungai yang sudah terbuka, namun masih berbatu dan dangkal. Pengambilan contoh dilakukan setiap minggu selama empat minggu di empat stasiun pengambilan contoh di Sungai Cigambreng. Lokasi pengambilan contoh dilakukan di area riffle dengan jarak antar stasiun sebesar $100 \mathrm{~m}$. Contoh makroavertebrata diambil menggunakan surber di 3 sub stasiun untuk masing-masing stasiun pengambilan contoh. Contoh kemudian dimasukkan dalam botol contoh dan diawetkan dengan formalin 4\%. Selain contoh makroavertebrata, parameter fisika dan kimia seperti lebar sungai, lebar badan sungai, kedalaman, arus, suhu, $\mathrm{DO}, \mathrm{BOD}_{5}$ dan $\mathrm{pH}$ juga diukur.

\section{Analisis Contoh}

Kepadatan makroavertebrata didefinisikan sebagai jumlah individu organisme per satuan luas $\left(\mathrm{m}^{2}\right)$ (Brower et al. 1990). Biomassa dihitung untuk setiap selang kelas sehingga didapatkan biomassa rata-rata per selang kelas. Penentuan biomassa diperoleh dari bobot dikalikan dengan jumlah individu.

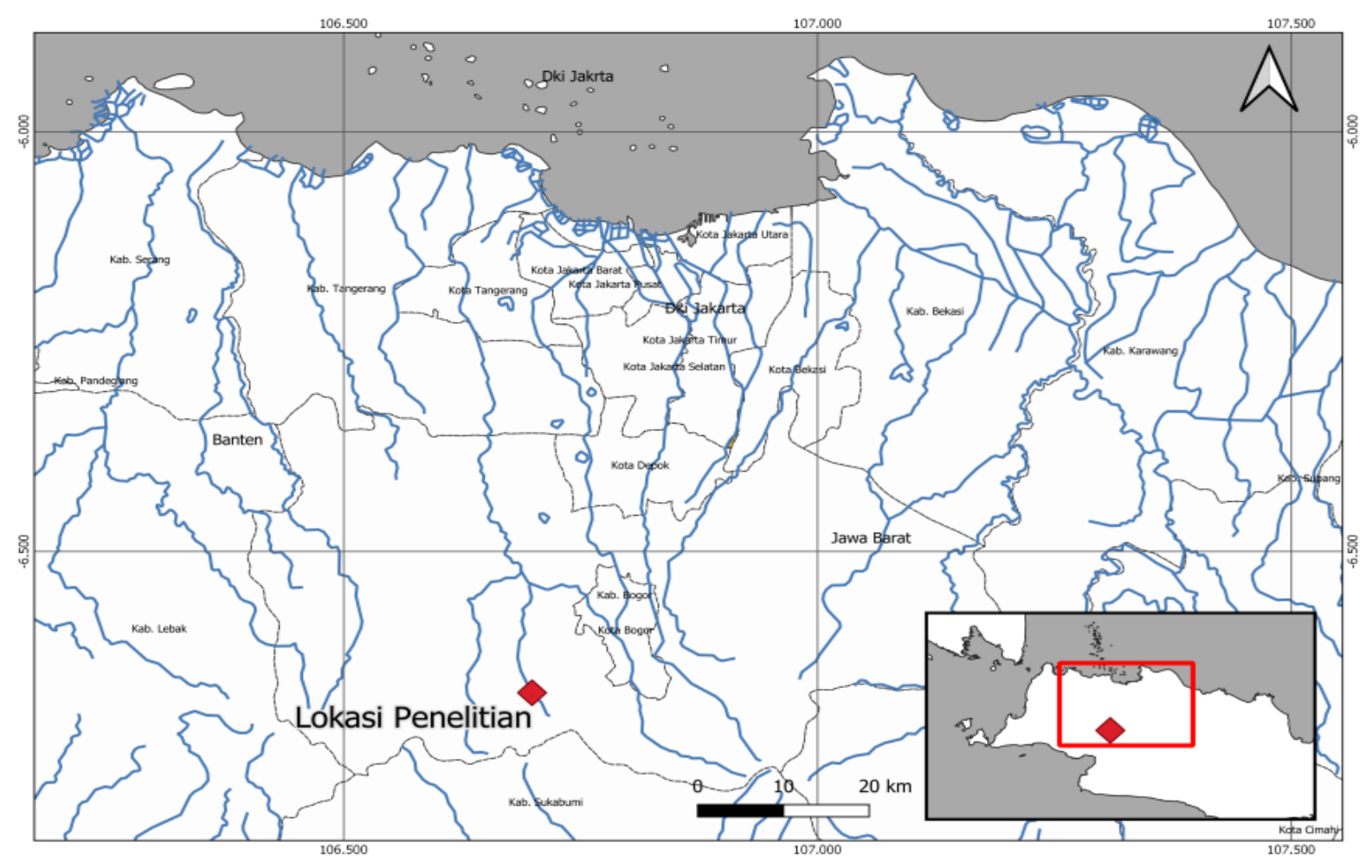

Gambar 1 Lokasi studi 
Bobot diperoleh dengan pendekatan biovolume. Pendekatan ini dilakukan dengan mengasumsikan tubuh larva sebagai tabung, sehingga volume dapat dihitung dengan mengukur panjang total dan lebar tubuh larva. Berat basah dan volume memiliki perbandingan 1,05 sedangkan berat kering dan berat basah memiliki perbandingan 0,142 , sehingga berat kering diperoleh dengan rumus sebagai berikut (Smith et al.1993).

$$
\text { Berat Kering }=0,1491 \times(\pi / 4) \times \mathrm{L}_{\mathrm{t}} \times \mathrm{W}_{\mathrm{t}}^{2}
$$

Keterangan:

$$
\begin{array}{ll}
\pi & =3,14 \\
\mathrm{~L}_{\mathrm{t}} & =\text { Panjang total } \\
\mathrm{W}_{\mathrm{t}} & =\text { Lebar total }
\end{array}
$$

\section{Analisis Data}

Produktivitas sekunder dianalisis dengan pendekatan non-kohort dengan metode frekuensiukuran (size-frequency method) atau metode SF. Metode ini menggunakan data panjang total untuk menyusun selang kelas ukuran. Data panjang total dikelompokkan dalam selang kelas. Penentuan selang kelas dilakukan berdasarkan Walpole (1992).

Analisis produktivitas sekunder dilakukan dengan menggunakan metode frekuensi-ukuran yang sudah dimodifikasi oleh Benke dan Huryn (2007). Produktivitas sekunder dihitung dengan rumus:

$$
P=\left[i \times\left(n_{j}-n_{j+1}\right) \times\left(W_{j}+W_{j+i}\right) / 2\right]
$$

Keterangan:

$\mathrm{P}=$ produktivitas sekunder tahunan $\left(\mathrm{g} / \mathrm{m}^{2} / \mathrm{bln}\right)$

$\mathrm{i}=$ jumlah kelas ukuran

$\mathrm{N}=$ jumlah total data selama pengambilan contoh

$\mathrm{n}=$ jumlah rerata individu pada masing-masing kelas ukuran
$\left(\mathrm{W}_{\mathrm{j}} \times \mathrm{W}_{\mathrm{j}+1}\right)^{0,5}=$ rerata geometri berat dari dua kelas ukuran.

\section{HASIL DAN PEMBAHASAN}

Hasil

Kondisi fisika-kimia perairan sungai Cigambreng dapat dilihat pada Tabel 1. Pada saat pengamatan, tercatat lebar badan sungai berkisar antara 5,4 m sampai dengan 11,6 $\mathrm{m}$ dan lebar sungai berkisar antara 3,2 m sampai dengan 6,8 m. Kedalaman sungai berkisar antara $11 \mathrm{~cm}$ sampai dengan $31 \mathrm{~cm}$. Arus di di sungai Cigambreng berkisar antara 0,3 sampai dengan $1,1 \mathrm{~m} / \mathrm{s}$. Nilai DO pada perairan sungai berkisar antara $5,2 \mathrm{mg} / \mathrm{L}$ sampai dengan $8,5 \mathrm{mg} / \mathrm{L}$. Suhu berkisar antara $22,3-23,5^{\circ} \mathrm{C}$. Nilai $\mathrm{pH}$ berkisar antara 7,4 - 7,74 dan $\mathrm{BOD}_{5}$ berkisar antara 1,1 $\mathrm{mg} / \mathrm{L}$ sampai dengan 3,2 $\mathrm{mg} / \mathrm{L}$. Secara umum, tidak ada perbedaan kondisi fisika kimia perairan di Sungai Cigambreng selama waktu pengamatan.

Jenis Famili Crambidae yang ditemukan terdiri dari dua genus yaitu Petrophila sp. dan Elophila sp. Selama empat kali pengamatan, kelimpahan Ordo Lepidoptera ini berkisar antara $100 \mathrm{ind} / \mathrm{m}^{2}$ sampai $422 \mathrm{ind} / \mathrm{m}^{2}$ (Gambar 2). Kelimpahan tertinggi didapatkan pada pengamatan pertama dan kelimpahan terendah didapatkan pada pengamatan ke tiga.

Produktivitas sekunder larva Famili Crambiadae dianalisis dengan menggunakan frekuendi-ukuran. Selain produktivitas selama satu bulan, disajikan pula data biomassa dan ratio kohort P/B. Hasil perhitungan secara lebih rinci disampaikan pada Tabel 2. Produktivitas selama satu bulan untuk larva Crambidae di Sungai Cigambreng adalah 47,7915 g/ $\mathrm{m}^{2} /$ bulan. Biomassa dalam satu bulan untuk larva Crambidae di bulan Oktober adalah 14,9669 g/ $\mathrm{m}^{2}$. P/B kohort selama satu bulan untuk larva Crambidae bernilai 3,1931.

Tabel 1 Hasil pengukuran parameter fisika-kimia perairan di Sungai Cigambreng

\begin{tabular}{lcccc}
\hline Parameter Kualitas Air & Sampling 1 & Sampling 2 & Sampling 3 & Sampling 4 \\
\hline Lebar Badan Sungai (m) & $6,3-10,7$ & $8,1-10,9$ & $5,4-11,6$ & $5,5-11,4$ \\
Lebar Sungai (m) & $3,6-6$ & $3,2-6,8$ & $3,8-6,4$ & $3,9-6,2$ \\
Kedalaman (cm) & $14,0-28$ & $11.0-26$ & $15,0-31$ & $14,0-26,5$ \\
Arus (m/s) & $0,6-0,9$ & $0,3-1,1$ & $0,6-0,8$ & $0,5-1,0$ \\
DO (mg/L) & $7-7,5$ & $5,2-7,6$ & $7,5-8,1$ & $6,2-8,5$ \\
Suhu $\left({ }^{\circ} \mathrm{C}\right)$ & $22,8-23,5$ & $22,3-23,5$ & $23,1-23,5$ & $23,1-23,5$ \\
pH & $7,50-7,65$ & $7,40-7,74$ & $7,46-7,57$ & $7,59-7,70$ \\
$\mathrm{BOD}_{5}(\mathrm{mg} / \mathrm{L})$ & $1,1-4,4$ & $2,2-3,0$ & $2,9-6,3$ & $2,5-3,2$ \\
\hline
\end{tabular}




\section{Pembahasan}

Penyebaran komunitas makroavertebrata dipengaruhi oleh kondisi lingkungannya. Parameter fisik dan kimia sangat mempengaruhi pola distribusi serangga air karena beberapa spesies sangat rentan terhadap polusi sementara yang lain mungkin lebih toleran terhadap kerusakan lingkungan (Mohammed et al. 2012).

Selain itu, morfologi habitat juga sangat mempengaruhi distribusi spasial dari makroavertebrata sungai (Pastuchova et al. 2010; Sheldon \& Walker 1998).

Keberadaan Famili Crambidae (Ordo Lepidoptera) di perairan sungai sangat dipengaruhi oleh kondisi fisik sungai. Sungai

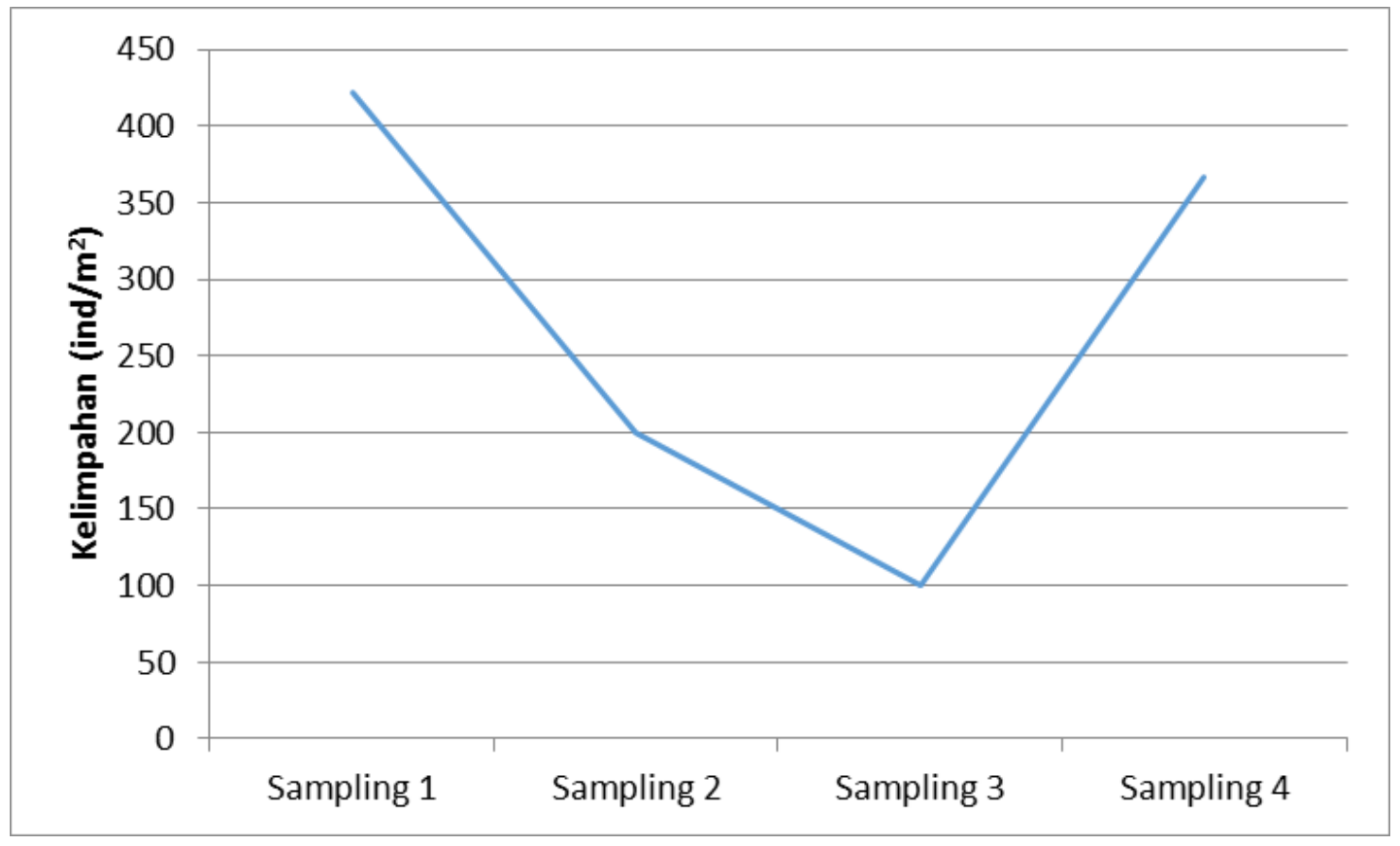

Gambar 2 Kelimpahan Famili Crambidae selama pengamatan

Tabel 2 Produktivitas Sekunder Famili Crambidaedi di Sungai Cigambreng pada bulan Oktober

\begin{tabular}{|c|c|c|c|c|c|c|c|}
\hline $\begin{array}{l}\text { Panjang } \\
(\mathrm{mm})\end{array}$ & $\begin{array}{l}\text { Kelimpahan } \\
\left.\text { (ind } / \mathrm{m}^{2}\right)\end{array}$ & $\begin{array}{c}\text { Massa } \\
\text { individu } \\
(\mathrm{mg})\end{array}$ & $\begin{array}{c}\text { Kelimpahan } \\
\text { yang hilang } \\
\left(\text { ind } / \mathrm{m}^{2}\right)\end{array}$ & $\begin{array}{c}\text { Biomassa } \\
\left(\mathrm{g} / \mathrm{m}^{2}\right)\end{array}$ & $\begin{array}{l}\text { Massa } \\
\text { yang } \\
\text { hilang } \\
(\mathrm{mg})\end{array}$ & $\begin{array}{l}\text { Biomassa } \\
\text { yang } \\
\text { hilang } \\
\left(\mathrm{g} / \mathrm{m}^{2}\right)\end{array}$ & $\begin{array}{l}\text { Waktu jumlah } \\
\text { ukuran kelas } \\
\left(\mathrm{g} / \mathrm{m}^{2} / \text { bulan }\right)\end{array}$ \\
\hline 2,635 & 267 & 2,0104 & & 0,5361 & & & \\
\hline 4,466 & 311 & 4,0247 & -44 & 1,2521 & 3,0176 & $-0,1341$ & $-1,0729$ \\
\hline 6,297 & 167 & 8,9463 & 144 & 1,4910 & 6,4855 & 0,9368 & 7,4944 \\
\hline 8,128 & 122 & 19,9238 & 44 & 2,4351 & 14,4351 & 0,6416 & 5,1325 \\
\hline 9,959 & 122 & 29,4573 & 0 & 3,6003 & 24,6906 & 0,0000 & 0,0000 \\
\hline 11,79 & 78 & 47,2051 & 44 & 3,6715 & 38,3312 & 1,7036 & 13,6289 \\
\hline 13,621 & 0 & 0,0000 & 78 & 0,0000 & 23,6026 & 1,8358 & 14,6860 \\
\hline 15,452 & 22 & 89,1300 & -22 & 1,9807 & 44,5650 & $-0,9903$ & $-7,9227$ \\
\hline & & & 22 & & 89,1300 & 1,9807 & 15,8453 \\
\hline & & & & & \multicolumn{2}{|c|}{ Produksi $\left(\mathrm{g} / \mathrm{m}^{2} / \mathrm{bln}\right)$} & 47,7915 \\
\hline & & & & & \multicolumn{2}{|c|}{$\operatorname{Biomassa}\left(\mathrm{g} / \mathrm{m}^{2}\right)$} & 14,9669 \\
\hline & & & & & \multicolumn{2}{|c|}{ Kohort P/B) } & 3,1931 \\
\hline
\end{tabular}


Cigambreng merupakan perairan sungai yang sudah terbuka, namun masih berbatu dan dangkal. Menurut river continuum concept, pada tipe sungai ini, sumber makanan sudah berupa autochtonou dimana sumber bahan organik berasal dari produktivitas primer organisme autotrof (Vannote et al. 1980). Sebagai organisme grazer (Stoops et al. 1998), Famili Crambidae merupakan salah satu yang akan memanfaatkan bahan makanan dari produsen primer terutama dari perifiton.

Berdasarkan Gambar 2, kelimpahan berfluktuasi sepanjang pengamatan. Terlihat kelimpahan Ordo Lepidoptera paling tinggi pada pengamatan pertama dan keempat, dimana bahan organik $\left(\mathrm{BOD}_{5}\right)$ menunjukkan nilai yang lebih rendah sehingga diduga kelimpahannya tidak dipengaruhi oleh keberadaan bahan organik. Hal ini mendukung pernyataan dimana Ordo Lepidoptera adalah jenis grazers dimana ia memanfaatkan tanaman/perifiton sebagai sumber makanannya. Perlu menjadi perhatian bahwa, penelitian lebih lanjut terkait korelasi antara bahan organik dan Ordo Lepidoptera ini perlu dilakukan untuk mengetahui keterkaitan keduanya secara lebih rinci.

Kisaran nilai $\mathrm{pH}$ di perairan Sungai Cigambreng tercatat berkisar antara 7,4 - 7,74 dan tidak ada perubahan drastis antara waktu pengamatan. Menurut Dallas et al. (1999), nilai $\mathrm{pH}$ yang masih mendukung kehidupan makroavertebrata di perairan berkisar antara 5,3 8,58 . Nilai DO yang tinggi sejalan dengan suhu perairan yang cukup dingin dan kondisi perairan berarus yang mendukung difusi oksigen dari atmosfer ke air.

Produktivitas sekunder Famili Crambidae bernilai cukup tinggi dengan nilai $47,7915 \mathrm{~g} / \mathrm{m}^{2} /$ bln dengan biomassa terbentuk sebesar 14,9669 $\mathrm{g} / \mathrm{m}^{2}$. Nilai tersebut cukup tinggi, namun Dolbeth et al. (2012) menyatakan bahwa metode SF dapat mengestimasi produktivitas terlalu tinggi (over estimate). Selain itu, menurut Benke (1993) terdapat bias yang diperoleh apabila perkembangan organisme memakan waktu yang lebih rendah atau lebih lama dari satu tahun.

Rasio P/B Famili Crambidae bernilai 3,1931. Rasio P/B merupakan hal yang sangat penting dalam memahami konsep produktivitas sekunder. Biomass (B) adalah jumlah massa jaringan tubuh yang terdapat dalam suatu populasi pada waktu tertentu dan produktivitas $(\mathrm{P})$ adalah aliran energi $\left(\mathrm{g} / \mathrm{m}^{2} /\right.$ tahun) (Benke \& Huryn 2007). Nilai P/B ratio dapat berkisar antara $<1$ hingga $>100$ dengan rata-rata $<6$ tergantung jenis organismenya. Selain itu, nilai $\mathrm{P} / \mathrm{B}$ dipengaruhi oleh keberadaan makanan, kualitas makanan, keberadaan substrat dan suhu (Benke 1993). Selain itu, nilai $\mathrm{P} / \mathrm{B}$ juga dipengaruhi oleh masa hidup suatu organisme. Benke et al. (1984) mengatakan bahwa nilai $\mathrm{P} / \mathrm{B}$ bervariasi dari $<10$ pada organisme yang cukup lama hidupnya (1 - 2 generasi per tahun) dan $>70$ pada organisme yang sangat pendek masa hidupnya. Khusus untuk lepidoptera sendiri, menurut Kunluang et al. (2019) termasuk univoltine yaitu hanya ada satu generasi setiap tahun. Walaupun ada jenisjenis lain yang termasuk uni-, bi-, maupun multivoltine.

\section{KESIMPULAN}

Ordo Lepidoptera yang ditemukan di Sungai Cigambreng pada bulan Oktober 2019 terdiri dari Famili Crambidae dengan dua spesies yaitu Petrophila sp. dan Elophila sp. Produktivitas sekunder Famili Crambidae di perairan Sungai Cigambreng selama satu bulan sebesar 47,7915 g/ $\mathrm{m}^{2} / \mathrm{bln}$, biomassa yang terbentuk sebesar 14,9669 $\mathrm{g} / \mathrm{m}^{2}$ dan $\mathrm{P} / \mathrm{B}$ ratio sebesar 3,1931 .

\section{DAFTAR PUSTAKA}

Benke AC, Huryn AD. 2007. Secondary production of macroinvertebrates. Di dalam: Hauer FR, Lamberti GA (editor). Methods in Stream Ecology 2nd edition. London (UK): Academic Press.

Benke AC, Van Arsdall TC Jr, Gillespie DM, Parish FK. 1984. Invertebrate productivity in a subtropical blackwater river. BioScience. 34 (7):443-444.

Benke AC. 1993. Concepts and patterns of invertebrate production in running waters. Verhandlungen des Internationalen Verein Limnologie. 25:15-38.

Brower JE, Zar JH, Von Ende CN. 1990. Field and laboratory methods for general ecology. Iowa (US): Wm C Brown Co Publisher.

Carlisle DM, Clements WH. 2003. Growth and secondary production of aquatic insects along a gradient of $\mathrm{Zn}$ contamination in Rocky Mountain streams. Journal of the North American Benthological Society. 22(4): 582-597.

Carneiro E, Silva LB, da Silva AF, Lopes GN, Pavan BE, Rodrigues RHF, Carvalinho DT, Mielezrski DF. 2018. Lepidopteran pests associated with the soybean cultivars phenology. Bioscience Journal. 34:112-121.

Cesar II, Armendariz LC. 2005. Secondary production of Chasmagnathus granulates (Crustacea; Decapoda) in Ramsar Site from Argentina. Braz. J. Biol. 67(2):235-241.

Dallas HF, Janssens MP, Day JA. 1999. An aquatic macroinvertebrate and chemical database for riverine ecosystems. Water $S A$. 25(1):1-8.

Dolbeth M, Cusson M, Sousa R, Pardal MA. 
2012. Secondary production as a tool for better understanding of aquatic ecosystem. Canadian Journal of Fisheries and Aquatic Sciences. 69:1230-1253.

Kunluang S, Yasanga T, Suang S, Manaboon M. 2019. Morphological study of the reproductive system and ovarian growth of the univoltine bamboo borer, Omphisafuscidentalis (Hampson, 1896) (Lepidoptera: Crambidae). Invertebrate Reproduction \& Development. 63(3):156164.

Mohammed AZ, Siddiq OL, Olayemi IK, Ayanwale AV. 2012. Spatial distribution of lake-water insect in Minna, North Central Nigeria: Bio-indication of water quality. International Journal of Applied Biological Research. 4(1\&2):57-64.

Pastuchova Z, Greskova A. Lehotsky M. 2010. Spatial distribution pattern of macroinvertebrates in relation to morphohydraulic habitat structure: perspectives for ecological stream assessment. Polish Journal of Ecology. 58:347-360.

Sheldon F, Walker KF. 1998. Spatial distribution of littoral invertebrates in the lower MurrayDarling River system, Australia. Marine and Freshwater Research. 49:171-182.

Smith H, Heel ED, Wiersma S. 1993. Biovolume as tool in biomass determination of Oligochaeta and Chironomidae. Freshwater Biology. 29:37-46.

Stoops CA, Adler PH, McCreadie JW. 1998. Ecology of aquatic Lepidoptera (Crambidae: Nymphulinae) in South Carolina, USA. Hydrobiologia 379:33-40.

Tofangsazi N, Cherry RH, Meagher RL, Arthurs SP. 2014. Tropical sod webworm (Lepidoptera: Crambidae): a pest of warm Sseason Turfgrasses. Journal of Integrated Pest Management. 5(4):C1-C8.

Vannote RL, Minshall GW, Cummins KW, Sedell JR, Cushing CE. 1980. The river continuum concept. Canadian Journal of Fisheries and Aquatic Sciences. Sci. 37:130137.

Walpole RE. 1992. Pengantar statistika edisi ke3. Jakarta (ID): Gramedia Pustaka Utama. 